\title{
Através do Click
}

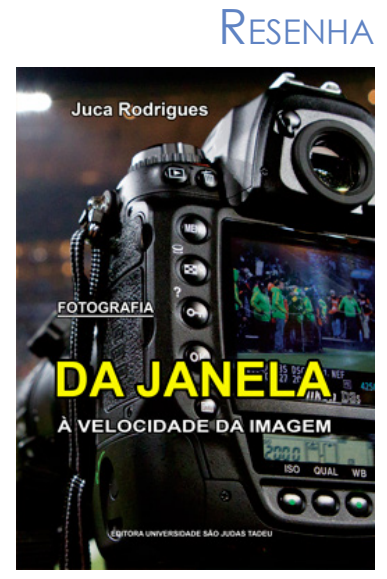

\section{Marion Neves Augusto}

Mestranda em Comunicação pela Universidade Municipal de São Caetano do Sul (USCS). Docente nos cursos MBA em Marketing e Vendas, MBA em Gestão de Projetos, MBA em Gestão de Pessoas, MBA em Gestão de Negócios e Psicologia Organizacional nas Faculdades Anhanguera, São Bernardo do Campo-SP. Email: marionaugusto@aedu.com.

Vivemos na época das imagens. Hoje, ver e olhar são verbos que determinam muitas coisas e muitas das nossas atitudes. O autor do livro Da janela, À velocidade da imagem, Juca Rodrigues, afirma que no mundo as coisas só podem ser percebidas pela linguagem visual, frase onde se revela o conceito fundamental da arte da fotografia, objeto de seu livro.

Juca Rodrigues é bacharel em Jornalismo pela Faculdade Cásper Líbero e especialista em criação visual e multimídia pela Universidade São Judas Tadeu, onde também é professor na área de Comunicação Social. Com 30 anos de atuação no mercado, exerce a função de editor de Núcleo de Fotografia da agência IstoÉ. Foi editor de texto e gerente de conteúdo dos sites IstoÉ, IstoÉ Dinheiro e IstoÉ Gente.

O livro teve como objetivo expor o acervo de parte de registros fotográficos em que o autor olha sensivelmente o mundo através da janela de automóvel. As imagens registradas por ele não são enquadradas, montadas ou editadas, dando margem à beleza do acaso.

O autor conta que, como bom apaixonado por fotografia, seus trabalhos não se encerram nas grandes mídias. Inspirado pela ideia do trânsito, onde as pessoas passam boa parte do tempo dentro de algum carro, ônibus, táxi, dirigindo ou mesmo de carona, criou o projeto fotográfico "Da Janela".

O livro é dividido em quatorze partes, sendo elas intituladas: O discurso fotográfico; Precursores e pioneiros da fotografia; A fotografia torna-se popular; A fotografia 
digital; Como funciona uma câmera fotográfica; Esquema básico de uma câmera fotográfica; Todas as cores e iluminação; Enquadramento, ponto de vista, composição e movimentos da câmera; O fotojornalismo; A fotografia publicitária; Direção fotográfica e criação da imagem; Equipamentos fotográficos e de iluminação; Fluxo digital básico para fotógrafos; Quem é quem na fotografia.

O primeiro capítulo aborda como fotografar uma cena, sendo essa a primeira dúvida dos fotógrafos que pensam no trabalho a ser desenvolvido. A primeira parte mostra que a fotografia em si representa um dos modos como o fotógrafo apresenta ao mundo o que ele viu, sendo algo muito pessoal, onde há uma relação unicamente entre o olho e a câmera.

Ao abordar as origens da fotografia, lembra que a palavra designa escrita da luz, expressão vinda do grego e da junção dos termos $f o z$ (luz) e grafi (escrita). O autor aponta que a fotografia não surgiu de uma hora para outra e, desde os primórdios até seu início efetivo, envolveu várias áreas do conhecimento, como química, física, matemática, filosofia e pintura. A fotografia surgiu oficialmente na França no século XIX, precisamente em 7 de janeiro de 1839, quando o cientista François Arago anunciou na Academia Francesa de Ciências, em Paris, que o pintor e cenógrafo Louis-Jacques-Mandé Daguerre havia desenvolvido um processo de captação e fixação de imagens, o qual denominou dedaguerreótipo.

$\mathrm{Na}$ terceira parte do livro é apresentada a empresa Kodak e seu slogan, "Você aperta o botão, nós fazemos o resto", frase que anunciou em 1888 a chegada da primeira câmera popular da história e sinalizou a disseminação da fotografia pelo mundo. Após a expansão das vendas de máquinas fotográficas, outras centenas de fabricantes desenvolveram novas câmeras, lentes e acessórios, estimulando nos usuários a busca pelos novos equipamentos, mais modernos e menos robustos.

Em seguida, o autor apresenta as mudanças da fotografia para a era digital, levantando a questão: até que ponto as inovações podem servir tanto para o bem quanto para o mal? O ponto central do questionamento é o aprimoramento e a popularização das câmeras digitais, possibilitando a qualquer pessoa fazer uma boa foto e, com isso, diminuindo a ação criativa ou humana do trabalho profissional. Com o advento do meio digital, levantaram-se questões a respeito da manipulação de imagens, ainda discutidas, atualmente, no que diz respeito, por exemplo, a mulheres (atrizes, modelos) sendo apresentadas com aparência de bonecas de plástico devido ao uso exacerbado do programa Photoshop.

O quinto capítulo cita os diversos tipos e tamanhos de lentes com potencial de captar a imagem em diferentes ângulos. Faz um alerta aos profissionais sobre a importância de entregar o trabalho conforme o layout ou publicação desejada. 
O autor, no sexto capítulo, detalha o funcionamento da câmera fotográfica. Destaca a semelhança do processo com o mecanismo do olho humano e particularidades técnicas que devem ser dominadas pelo profissional de fotografia.

No sétimo capítulo, o autor explica que, mesmo a fotografia tendo nascido nas cores preta e branca, as possibilidades atuais com as diversas cores e efeitos de tons fazem com que o profissional leve em conta o conceito do trabalho a ser realizado e, a partir daí, pense nas tonalidades da imagem e cores propriamente ditas, sem exageros.

Segundo o autor, os fotógrafos amadores geralmente usam a câmera fotográfica para determinado assunto, muitas vezes, sem conhecimento técnico do que estão fazendo. Enquadrar significa delimitar a imagem, decidir o que entra e o que fica de fora em uma foto, elegendo uma cena ou os elementos que sejam interessantes se mostrar. No oitavo capítulo, explica que no campo ou cenário tudo deve ser pensando por quem está fotografando. Não se deve apontar a câmera para uma cena sem se ter em mente o resultado, postura que tipifica o olhar fotográfico e difere profissionais de amadores.

No capítulo nove, alguns aspectos sobre o fotojornalismo são apresentados como fatores primordiais para o profissional da área, uma vez que, nos dias de hoje, o conhecimento profissional necessário para o exercício dessa função evolui em termos instrumentais e processuais. O trabalho do profissional de fotojornalismo deve ser feito em uma velocidade cada vez maior, atendendo às demandas editoriais que chegam a se estender do jornalismo para a publicidade. Por fim, se faz necessário apontar dúvidas e propor soluções visando aprimorar o trabalho do profissional e valorizar seus aspectos editoriais e éticos, pois a produção jornalística é moldada pelas premissas da empresa contratante e sua publicação é decidida pelo editor.

Ao falar sobre fotografia publicitária, no décimo capítulo, o autor aponta que é a área do mercado que mais movimenta dinheiro. Tudo, nela, é pensado beirando a perfeição, com o intuito de persuadir o consumidor. Utilizar a fotografia para vender mercadorias não foi algo cogitado de imediato por jornais e revistas. Seu uso criativo em anúncios publicitários começou de forma tímida no final dos anos 1920. A publicidade que conhecemos hoje, com agências estabelecidas e anunciantes, só apareceu no final do século XIX. Atualmente, no Brasil, é comum o fotógrafo receber valores fechados por toda a produção, sendo ele responsável pela contratação de modelos, locações, equipamentos, cenários, dentre outros.

No que tange à direção fotográfica e criação de imagem, o autor salienta que fotografar é marcadamente um ato solitário e introspectivo (por serem parte dele apenas o fotógrafo, sua câmera e o assunto), mas para a produção de um trabalho é necessária a participação de pessoas e equipe que organizem e auxiliem nas atividades de planejamento 
e de campo. No fotojornalismo imediato, em que os acontecimentos são imprevistos, o profissional tem de pensar rapidamente em qual ação tomará a fim de reverter problemas. Para os trabalhos com maior tempo, é importante definir qual a ideia central a ser transmitida. Na publicidade, deve-se determinar quais elementos serão fundamentais tendo em vista o briefing e indicações no layout. A decisão possibilitará que se tenha o conceito da foto ou ideia da imagem a ser produzida.

O capítulo doze discorre sobre a importância dos equipamentos fotográficos e da iluminação, afetados pelos lançamentos e avanços tecnológicos que proporcionam a diminuição do tamanho e aumento da qualidade dos aparelhos. A crescente variedade de câmeras fotográficas e acessórios sofisticados viabiliza trabalhos de alto nível. Para alguns especialistas, há previsão do fim de equipamentos profissionais num futuro próximo, quando serão substituídos pelos ultramodernos smartphones com capacidade de fotografar em alta resolução e lentes desenvolvidas pelos melhores fabricantes da fotografia tradicional.

O autor aborda o fluxo digital mencionando que o processo de tratamento da imagem, advindo da tecnologia digital, é tão importante quanto o ato de fotografar. Anteriormente, o fotógrafo entregava o filme ao laboratório e só via seu trabalho após a revelação. Com o processo digital, ele mesmo pode revelar as fotos, ou seja, manipular o arquivo gerado pela câmera e entregar o trabalho nos padrões técnicos e estéticos de sua preferência.

No último capítulo, o autor relaciona bons fotógrafos ao longo da história em um panorama da produção fotográfica mundial. Apresenta nomes e seus respectivos trabalhos, que constituem referências até para profissionais do ramo.

RODRIGUES, Juca. Da janela, À velocidade da imagem. São Paulo: Ed. Universidade São Judas Tadeu, 2014. 